Article

\title{
Perceiving and Deflecting Everyday Poverty-Related Shame: Evidence from 35 Female Marriage Migrants in Rural China
}

\author{
Guanli Zhang \\ Department of Sociology, Tsinghua University, 100084 Beijing, China; E-Mail: sant3890@mail.tsinghua.edu.cn
}

Submitted: 28 November 2019 | Accepted: 10 February 2020 | Published: 28 April 2020

\begin{abstract}
This research examines how poverty is perceived and deflected by a group of female cross-provincial marriage migrants in contemporary rural China. It presents accounts of poverty-related shame in everyday village life. Known as migrant wives, respondents in this research have experienced both absolute and relative poverty over the course of their lives. The personal lament of insufficiency and the social discourse of poverty respectively underpin internal and external povertyrelated shame. Correspondingly, migrant wives employ strategies of recounting misery and redefining identity to normalise their poverty and their stigmatised social image, hoping to mitigate the psychological and social impacts of shame. This research contributes an empirical analysis to our understanding about the origin, manifestation, and impact of povertyrelated shame, which is usually a neglected consideration in poverty studies. It also sheds light on the gender-specified risks, burdens, and social expectation that affect migrant wives' perception and experience of poverty.
\end{abstract}

\section{Keywords}

marriage migration; migrant wives; poverty; poverty-related shame; rural China

\section{Issue}

This article is part of the issue "Left Behind? Women's Status in Contemporary China" edited by Robert Walker (Beijing Normal University, China) and Jane Millar (University of Bath, UK).

(C) 2020 by the author; licensee Cogitatio (Lisbon, Portugal). This article is licensed under a Creative Commons Attribution 4.0 International License (CC BY).

\section{Introduction}

As a number of multi-sited poverty studies indicate, a universal and immutable link between poverty and shame has long existed in human society (Chase \& BantebyaKyomuhendo, 2014; Walker, 2014; Walker et al., 2013). Poverty-related shame is externally imposed by the society, via individuals and through social institutions, and is further internalised as a powerful adverse emotion about insufficiency, hardship, degradation, and social exclusion. This definition highlights the intricate nature of poverty-related shame as a psychological and social process that involves multiple determinants at both individual and social levels. As Lister (2013) suggests, pain is "all too often associated with poverty: disrespect, humiliation and an assault on dignity and self-esteem; shame and stigma; and also powerlessness, lack of voice, and denial of full human rights and diminished citizenship." Discussion on shame as a negativity of poverty is both theoretically and practically significant, since it bridges understanding of how poverty challenges social norm and personal well-being by looking into the interaction of multi-level agencies. Following this path, the research adopts an original angle of vision to examine how poverty-related shame is perceived and deflected in an everyday context.

This article presents an account of poverty-related shame in contemporary rural China. It focuses on the phenomenon of cross-provincial marriage migration in the 40 years after the country's reform and openingup, when more than ten million rural residents, mostly female, left their natal villages and settled down in new communities through distant, inter-provincial marriage (Fan \& Huang, 1998; He \& Gober, 2003). The migration demonstrates a clear-cut geographic pattern: Economically advanced areas in East China are common destinations of the population influx (Liang \& Chen, 2004). Consequentially, cross-provincial marriage migra- 
tion is usually interpreted as an economically motivated phenomenon and an individualised effort of poverty alleviation (Bossen, 2007; Fan, 1996, 1999). As Bossen (2007) points out, female marriage migrants are subject to gender-specified risks and restrictions on their social mobility in particular: Marriage is perhaps the opportunity of a lifetime for them to climb up the social ladder. However, even though many female marriage migrants manage to step out from absolute poverty through migration, they have few choices but to marry into financially disadvantaged families, hence falling into the quagmire of relative poverty almost instantly after relocation (Fan \& Li, 2002; Jiang, Zhang, \& Sánchez-Barricarte, 2015). The fact that female marriage migrants usually have experienced both absolute and relative poverty makes them ideal subjects for understanding the psychological and social impact of poverty on individuals.

This research examines 35 female inter-provincial marriage migrants' everyday experience of poverty. The following narratives and analyses answer the key question of this research, i.e., how poverty-related shame is perceived and deflected by female marriage migrants in rural China. This article argues that poverty-related shame is not only an internal psychological feeling of insufficiency, but also an external socially fabricated discourse of identity. Female marriage migrants tend to employ misery recounting as an active strategy to neutralise poverty and mitigate internal shame. Meanwhile, they strive to integrate into the social mainstream and differentiate themselves from other disadvantaged groups so as to deflect the externally imposed shame derived from their social label as 'impoverished incomers' in the neighbourhood.

\section{Literature Review}

This research bridges three sets of literature: first, on the psychological and social impacts of poverty; second, on the gendered manifestations of poverty; and third, on the phenomenon of internal marriage migration in postreform China. It signifies the realm where poverty studies intersect with migration, gender, and family issues under the scope of social inequality. This article contributes to scholarship by offering empirical insights that contextualise the origin, manifestation, and impact of povertyrelated shame.

Years of academic research seeking the essence and the manifestation of poverty has acknowledged the multifaceted nature and multiple measurements of this phenomenon (Alkire et al., 2015; Kakwani \& Silber, 2008). Poverty not only describes a status of insufficiency and deprivation at the individual level, but also points to the inequitable distribution of resources in the society (Ravallion, 2001); it not only sets forth a number of material parameters to evaluate the scarcity, but also highlights the social expectation for well-being and affluence (Medeiros, 2006). Consequentially, poverty is invariably construed as a policy problem, given its foci on hu- man rights and social equality (Walker, 2014, p. 13). In this sense, the conceptualisation and visibility of poverty is inherently social and political (Walker, 2014, p. 5). The fact that poverty needs to be understood from the perspectives of both individuals and society underpins a dual-layer analytical framework, with which this research engages.

Poverty has long become part of people's everyday life. Much existing literature sheds light on how impoverished people internalise their experience of marginality, helplessness, dependency, and not belonging as daily routine (Daly \& Kelly, 2015) and how the degradation and the exclusion of the financially inferior groups becomes a normalised practice and discourse in society (Lang, 2011). Among many daily manifestations of poverty lies povertyrelated shame. According to Walker (2014, p. 2), shame has long been a 'missing consideration' of poverty. This research sheds light on poverty-related shame in everyday occasions by observing and analysing its origin and influence on the basis of personalised accounts.

The intellectual significance of examining China as a medium through which to comprehend poverty is twofold. The dichotomised urban-rural, dual-sector society in the transforming socialist regime sets the stage for understanding the relationship between poverty and inequality. The political classification of its people (Davis \& Wang, 2009), the household registration (hukou) system (Du, Park, \& Wang, 2005), the social division of welfare (Dollar, 2007), and the rapid implementation of privatisation that "allows some people to become rich first" (Chang, 2001) are among the most-cited discriminative policies that perpetuate long-standing inequality. In addition, as Li and Wei (2010) note, the regionally unbalanced development model exacerbates the disparity in wealth and resource holdings, rendering a spatial structure of poverty in the country. Complementary to the aforementioned structural factors is the nexus of poverty, culture, and social discourse in China. Li (2005) sheds light on the vulnerability of impoverished people in a discriminative social and political environment, whereas Solinger (2006) points out that the 'underclass' has already accepted its poverty as destiny. The culturally framed aetiology of poverty, e.g., laziness and lack of will power, constitutes the mainstream explanation for poverty (Gao, 2017). Since 1949, poverty has been downgraded from an indication of being spiritually advanced and reliable to a sign of backwardness and shame (Yang \& Walker, 2019). Both the structural backdrop and the cultural dimension of poverty in China contributes to our knowledge about the dynamics of this phenomenon. It provides a framework to understand how my respondents perceive and deflect poverty in their everyday life.

This article focuses on female inter-provincial marriage migrants. The phenomenon of distant marriage has been well discussed in both gender and migration studies. In China, marriage migration is chiefly undertaken by women (Davin, 1996, 2007). While the increasing number of marriage migrants and the enlarging pattern of 
marriage circle signifies higher social mobility of women, it also brings along a number of challenges to the migrants themselves. Marriage migration inevitably results in migrants' distant relocation and adaption of the postmarital patrilocal residence. In most cases, migrant wives are partially or utterly cut off from natal kin as a cultural arrangement (Fan \& Huang, 1998; Stockard, 1989). Meanwhile, they are simultaneously regarded as incomers in their husbands' families (Bossen, 2007; Zhang, 2009). Tan and Short (2004, p. 152) portray migrant wives as 'double outsiders.' They point out that their prevailing sense of disorientation after distant marriage manifests itself as persistent difficulties of identification, crisis in the newly established families, and failures of establishing and managing new social networks (Tan \& Short, 2004). Despite of the risks, millions of females opted for inter-provincial marriage as a way to enhance their life prospects. As Davin (2005) argues, marriage is among the very limited opportunities for women in rural China to climb the social ladder and get a better life. The economic incentives behind the choice of distant marriage shall never been neglected. Findings in this research resonate with the existing literature in the sense that they exemplify migrant wives' sacrifice of cultural and physical dislocation as a strategy of poverty alleviation. Noteworthy enough, the purposeful marriage exchange powered by economic incentives serves as an underlying reason for the unbalanced power relations between husband and wife and poses challenges to migrants' adaption and social inclusion (Bossen, 2007; He \& Gober, 2003). In this sense, the insight of migrant wives' perception and deflection of poverty is key to understand how they handle and react to the difficulty of identification, the gender-specified risks, and the burdens in their migration and marriage. This illuminates the significance of studying poverty-related shame facing migrant wives in rural China and outlines the article's theoretical and empirical contribution.

To sum up, this article takes a dual-layer approach to examine the structural and cultural manifestations and impacts of poverty with reference to the female marriage migrants in rural China. It pays attention to poverty-related shame at both individual and society levels. It marks the intersection of theories about poverty, poverty studies in China, and empirical research of China's internal marriage migration.

\section{Fieldwork and Research Methods}

This research is grounded in a series of investigations undertaken in a village in East China over the past five years. An 11-month on-site fieldwork was implemented in 2014 and 2015 , followed by three return visits. The time spent in the field enables time-lapse observations on a part of the research subjects' life course and the changing social settings in the locality. Such time-lapse ethnographic approach, as pointed out by Douglas (2019), reveals the dynamics and adds a stronger longitudinal diachronic ele- ment to data analysis. In a way, it constitutes the methodological originality of this research.

The research site is a village named Jiangbin. It is located on the outskirts of Hangzhou, the capital of Zhejiang Province. Jiangbin is an economically advanced industrialised village, thanks to its location and the regional development-boosting policies. The demographic features of this historic rural community have long been shaped by its capsular nature, with four dominating clans characterising the local kinship networks. Marriage in Jiangbin used to be confined within a geographically specified circle, which in return preserves the 'purity' of local culture. Since the 1980s however, villagers have observed an increasing number of migrants entering the neighbourhood. By 2018, the village accommodates about 4,000 people, of which approximately a third are migrant workers attracted by the thriving industries and job opportunities in the locality. Parallel to the occupation-driven population flow is the interprovincial marriage migration. Females comprise an absolute majority of the population married into Jiangbin over the past four decades. Female marriage migrants are referred to as migrant wives (wailai xifu) in the village. The number of migrant wives, according to the village committee of Jiangbin, reached 100 by 2018, and is still growing.

This research follows qualitative and ethnographic approaches in data collection. 35 female inter-provincial marriage migrants constitute the key respondents. They were mainly recruited through personal relations and snowballing, while a small number of respondents are a random sample from a name list provided by the village committee. All the interviews were conducted by the author. The duration of interviews ranges from 30 minutes to two hours each. The investigator used a topic guide to facilitate the semi-structured interviews, aiming at ensuring the quality of data. 11 sets of questions were designed, featuring their basic personal info, adaption to the local culture, family members, other social relations, relationship and financial arrangements with their natal kin, decision-making for the marriage and migration, post-marriage everyday life, identity, personal and family finance, perception and experience of poverty, and vision for the future. As part of the timelapse ethnographic approach, the investigator stayed in touch with all the interviewees via telephone or Wechat (weixin), a smartphone-based chatting tool popularised in China, so as to update their situation and arrange further meetings. In addition, interviews with ordinary villagers and village cadres, as means of triangulation, ensure the comprehensiveness and reliability of the qualitative data. A random sample of 12 local villagers were interviewed, in which the investigator collected their basic personal info and their opinions on the local marriage culture, the phenomenon of migrant wives, migration, gender, and poverty.

The 35 migrant wives constitute a sample of great heterogeneity. It covers a wide age spectrum from 24 
to 61. Respondents come from ten different provinces spreading across Middle and Southwest China. They can be divided into three age-graded cohorts following the paradigm of life-course analysis (Elder, Johnson, \& Crosnoe, 2003). Each cohort demonstrates characteristic features, reflected in the migrant wives' education level, motives of migration, interpretation of hardship in life, and social networks before and after marriage. However, interviews clearly demonstrated that all of the respondents have experienced absolute and relative poverty at different stages of their life course. Despite of the multiple factors that influenced the way how poverty-related shame is individually perceived and deflected, this article focuses on the respondents' common experience of marriage migration and quests after its correlation with the negativity of poverty. The research question points the direction for data selection and analysis in this article, where special attention has been paid to migrant wives' experience of migration, identity, and their connection with poverty-related shame.

In this research, data in forms of interview notes, transcriptions, fieldwork diaries, photos, and scanned archival documents have been archived and protected by encryption software. The fieldwork runs in accordance with the principle of inform consent. Pseudonyms for the village and the participating individuals are used to protect the respondents' privacy.

\section{Internal Shame and the Misery Recounting}

The aetiological complexity of migrant wives' internal shame is in the first place rooted in their life course. Associated with migrant wives' distant marriage is their multiple identity as incomers in the village, wives and mothers, impoverished people leaving their natal kin for a better life, and above all, financially inferior members of the community. Findings from Jiangbin underpin the causal links between poverty-induced shame and the dynamic process of identification. As Walker (2014, pp. 33, 106) suggests, 'the self' and 'the other' mark the 'dual points' of respondents' internal shame of poverty. This project sources and interprets migrant wives' internal feeling of shame by examining how they evaluate their own experience and respond to the social expectation.

Noticeably, the development gap between Jiangbin and the respondents' natal communities is a recurrent theme in their accounts of life trajectories before and after migration. Almost all of the migrant wives who settled in Jiangbin in the 1980s and the early 1990s mentioned the low living standard in their maternal families, where "parents struggled to feed the children." The description conforms with the definition of absolute poverty, which plots the scarcity of and the limited access to resources to cover basic human needs. Marriage exchange is among the very few options for young women to break away from financial destitution. The process inevitably results in the commodification of marriage and the associated fatalism and shame for their inferior financial and gender statuses. Female migrants referred to their decision of distant marriage as 'a final resort' to "officially depart from the impoverished life in the natal communities." They felt jealous of other wives married in from nearby areas of Jiangbin, who "did not necessarily need to 'vend' themselves in exchange for a decent life." In many cases, the migrant wives could not even instantly inform their parents of the wedding, let alone get financial and psychological support from their maternal families. This gives rise to the feelings of regret and shame. As for the marriage itself, some respondents reflected on the purposeful and commoditised marriage. They felt ashamed of the 'impure' marriage, which "resembled a transaction" they "had no option but to accept."

In addition to the previous experience of absolute poverty and the unequal economic status in the marriage, the finance of the nuclear family after marriage serves as another source of migrant wives' internal shame. Distant marriage is by and large an institutional arrangement to fulfil the needs of males who cannot find a partner or cannot afford to marry locally. As Zhang (2018) points out, it is either because of the inherent disadvantages of the husbands (e.g., age, appearance, intelligence, etc.) or the inferior financial status of the husbands' families. Therefore, the new nuclear family of a migrant wife is usually subject to material insufficiency. According to many of my respondents, relative poverty pertains after marriage, preventing them from climbing up the social ladder. They felt depressed because they "strived hard to make ends meet every year with little spare money left" and that "rich people got richer" while they "stayed poor despite of the great endeavour to earn and save money." The desperation manifests itself in the form of self-denial, which resonates with the definition of shame.

Poverty-related shame, reflected in migrant wives' everyday experience and self-denial, is internalised as a series of routinised practices and expressions. Female marriage migrants in Jiangbin usually start the conversation by framing poverty as an inescapable situation. "No way out of poverty" and "desperate about the future" are common responses to an impoverished life. Despite continuous effort to step away from poverty, significant financial improvement seldom takes place in migrant wives' families. According to the respondents, it is the structural factors that shape their inferior financial statuses, hardship, and the associated shame and desperation about the predicaments. Such shame on one hand arises from migrant wives' social identity, and on the other, persists to reinforce their identity through daily practices on the social stage (Goffman, 2009).

Among the migrant wives in Jiangbin, a most identifiable practice motivated by the poverty-related shame is recounting misery. Misery refers to the private experience of hardship. In Jiangbin, migrant wives' accounts of their misery centre on their experience of poverty before and after marriage. Rather than keeping the personal experience confidential, migrant wives tend to share their 
stories on various occasions and in different forms, ranging from daily complaints at home, small-talk in the neighbourhood, to statements in the public arenas such as the village committee. The practice of recounting misery is interpreted as a way to properly handle and deflect the poverty-induced internal shame. Through recounting hardship in daily settings, migrant wives strategically normalise the poverty-related shame, which in return entails a counterbalance to moderate their sense of disqualification and self-denial.

Recounting misery as a strategy to normalise internal shame manifests itself primarily as an attempt to neutralise its effect. It illustrates respondents' reflections on poverty as a common phenomenon pertaining to various temporal, geographical, and social settings. In the recitations, migrant wives present structural explanations to normalise their poverty and the associated feeling of shame. By doing so, poverty is neutralised as an externally determined status and a common experience of the whole generation from 'backward provinces' in China:

Every family in my village faced hardship and hunger at that time. There was no exception. We distributed crops on a per capita basis within the brigade [shengchandui]. The only things we could keep for ourselves were the remaining potatoes after harvest. My younger brothers and I used to spend hours after school searching in the field, round after round, till all the left-over potatoes were dug out. It was among the very few occasions we could eat as much as we want for dinner. (Ms. Jin, 55, from Lincang, Yunan, married into Jiangbin in 1989)

Every August, my dad had to sell home-made popcorn in the town five miles away to subsidise the kids' tuition. It was a hilly road and he had to go on foot. I went with dad once on a rainy day and I remember I could not even recognise the colour of my trousers under the muddy stains when we returned....My hometown is doomed to be poor because of its geographical conditions. It was a common situation for most of the West provinces. If it were as flat as here, we could have easier connections to the outside world and a more vibrant economy. (Ms. Yu, 51, from Fuling, Chongqing, married into Jiangbin in 1988)

Recounting misery takes place on everyday occasions within and without the circle of migrant wives. It usually resonates with the crowd, since middle-aged residents in rural China have, more or less, experienced insufficiency throughout their lives. When the experience of poverty becomes normalised in local discourse, migrant wives take a step further and frame the status of being able to live with poverty-induced hardship as a virtue. This enables them to normalise their struggles against relative poverty after marriage and to legitimate their recourse to external supporters, the strategies of which range from borrowing money from neighbours, claiming subsidies from the village, to receiving financial aid from the state:

I do not have the fortune to enjoy a good and easy life for even a single day after marrying into Jiangbin. My husband has three brothers. They could not afford to marry locally. All my sisters-in-law are migrant wives. I knew we could not end up living in the old family house for a lifetime, so I saved every penny to build our own house. Even in the first month after I gave birth to my son, I resumed part-time work as an umbrella-packer to subsidise the household....We [migrant wives] are apparently tougher in face of hardship than the local women. (Ms. Guan, 58, from Panxian, Guizhou, married into Jiangbin in 1983)

The normalisation of poverty and the justification of endurance in hardship through the recounting of misery is psychologically beneficial to the migrant wives. Such accounts frame poverty as a structural result of unbalanced development, a common life experience for the generation, and a challenge to which they respond with perseverance and diligence. Their accounts decrease the impact of internal shame. Recounting misery also gives rise to a sense of common identity among the migrant wives. By imagining hardship as a neutral or even positive life experience, migrant wives justify their struggle against poverty and differentiate themselves from local brides. In this sense, hardship becomes a source of dignity rather than shame for the female marriage migrants in Jiangbin.

Nevertheless, when it comes to the competition for material benefits, recounting misery seldom wins the impoverished migrant wives any advantage. Even though some respondents publicly expressed hardship so as to justify their recourse for aid and benefits, they soon realised that the distribution of benefits for poverty alleviation is determined by other mechanisms, e.g., the established administrative process or informal social connections (guanxi) in the locality. The accounts of chronic poverty and insufficiency cannot necessarily compensate for migrant wives' limited social capital in the struggle for material resources.

\section{External Shame and the Dynamic Approaches of Identification}

Complementing internally generated self-denial and disqualification, external shame serves as another psychological manifestation of poverty among the migrant wives in Jiangbin. As Scheff (2003) suggests, shame itself is inherently social. It is intricately connected to one's social identity and to the process of identification. Social identification emerges in the interaction between individuals and social groups $\mathrm{s} /$ he belongs or does not belong to (Ellemers, van Knippenberg, de Vries, \& Wilke, 1988). It is conceptualised via the cognitive and social process of association and differentiation (Hogg \& Terry, 
2000). Jiangbin, as a space that accommodates migrant wives' social connections and activities after marriage, outlines the realm where social inclusion and exclusion takes place. The way cross-provincial marriage migration is perceived in the village plays a pivotal role in the formation of migrant wives' identity and serves as a source for their external shame. In Jiangbin, migrant wives' identity is usually defined according to their natal origins and their inferior financial status before and after migration. In this sense, poverty and alienation are usually intertwined. They simultaneously mark the sources of the externally produced shame from the community.

External shame has its root in the prevalence of prejudice against poverty in Jiangbin. Many respondents reported that they were not adequately valued in the village as a qualified wife, mother, and village member because of their disadvantageous financial status. As observations from Jiangbin indicate, migrant wives' experience of external shame has become a part of the community culture and structure. Culture wise, local villagers in Jiangbin tend to emphasise the causal relations between diligence and fortune. Correspondingly, they usually cite laziness as the reason for poverty. This echoes with the World Values Survey, which shows a high percentage of the population in East Asian countries reckoning poverty as a result of laziness and lack of willpower (Walker, 2014, p. 134). The mechanism of social stigmatisation streamlines the multiple causes behind poverty and associates it with distain and contempt for individuals. In addition, the dominant masculine discourse in the village prescribes a set of social expectations on female members. Apart from the obligations of reproduction and care (for both the old and the young), women married into the village are also expected to maintain the family budget, to take up household chores, and to contribute an income by assuming paid work (Cook \& Dong, 2011). These high expectations exhausted many respondents, who complained about "relentlessly spinning day by day." Worse still, migrant wives that fail to meet the social expectation are shamed publicly. This exemplifies another source of external shame in female migrants' life experience, which, according to Walker (2014, p. 110), is usually gender-specified.

In addition, external shame is also reinforced by geographic settings and social relations in the community. The geographic intimacy among households and the condensed social networks in the locality set the stage on which external shame can exist, develop, and influence the impoverished female migrants. In Jiangbin, the shaming process usually takes place on everyday occasions, ranging from quarrels between female migrants and their family members, comments on each other's family life, small-talk in groups, to the village-wide evaluation of a household's financial status. Densely fabricated formal and informal channels of information in the social space of Jiangbin makes it hard for the villagers to maintain their privacy. It is through everyday social interactions that impoverished families are named and shamed.
Consequentially, poverty-related external shame manifests itself in the process of labelling, in which migrant wives are simultaneously identified as incomers and financially inferior members of the community. Such social exclusion denotes the form of external shame experienced by many respondents.

While migrant wives have spotted ways to moderate internal shame by actively fabricating discourse about poverty, the extent to which such accounts mitigate external shame cast by the community remains questionable. The social impact of normalising poverty by recounting misery is usually confined at an individual level or within groups of migrant wives of a similar background. Given their inadequate social capital, migrant wives could hardly change or influence the mainstream value in the community however enthusiastically they broadcast the way they live with and fight against hardship. They have no choice but to integrate themselves into the mainstream of the community. It is through practicing the mainstream value and redefining their identity that migrant wives manage to handle and minimise the impact of poverty-related external shame on their everyday life. Observation suggests that the pursuit of a new identity comprises the individualised endeavour of integration and intentional differentiation with other disadvantaged groups.

Instead of resigning themselves to external shame, most migrant wives choose to keep up appearances in their everyday social life. Their individualised efforts of integration range from learning and speaking the local dialect, dropping in around the neighbourhood for chats, and joining the women's federation (fulian) of the village. Nevertheless, these endeavours only entail acceptance to a limited extent, whereas the migrant wives in Jiangbin yearn for due respect from the community. The insurmountable gap between expectation and reality serves as another source of external shame. Many respondents believe that the absence of respect is rooted in their inferior financial statuses. Poverty brings about contempt rather than sympathy in the local culture. Following the initiative of stepping out from poverty, most migrant wives have to work excessively towards the improvement of family finance. They positively respond to their poverty-related external shame by accepting, adapting to, and practicing mainstream values prescribed to women. As Ms. Ran remarked below, excessive hard work is the only solution to reconstruct her social identity, to gain recognition from the community, and to help the next generation avoid an interprovincial marriage:

I work in the factory eight hours a day and I do another part-time job of sewing curtain edges in the evening. The work ruined my knees and my eyes....Why do I work so hard? It is all for the sake of my son. I do not want him to marry out, nor do I want a daughterin-law from a remote province. I know every bit of the hardship to marry out remotely. It means hard- 
ship, not only for the bride, but also for the couple and the whole family. We are not a rich family at all, but I will spare no effort to earn a house and a car for my son before he gets married. I am now living a life like most middle-aged women in East Xiaoshan: If I did not work and went to play cards in the teahouse, I would be criticised by the whole village as an unqualified mother and wife. (Ms. Ran, 48, from Youyang, Chongqing, married into Jiangbin in 1996)

Ms. Ran is not alone. Most migrant wives in Jiangbin adopt similar individualised strategies to cope with poverty-induced external shame. They are eager to be rid of their social image as incomers from impoverished areas. At the same time, they have an urgent need for an improved financial status. In this sense, the reconstruction of an identity according to local values and social expectations is of both psychological and material significance for the migrant wives.

Apart from localising themselves by embracing the mainstream and positively responding to normative social expectations, migrant wives also seek 'others' to differentiate themselves from so as to reinforce their identity as being 'native.' The comparison gives rise to a sense of confidence and satisfaction, which in turn mitigates their poverty-related external shame. The fact that Jiangbin accommodates more than 1,000 migrant labourers working temporarily in the nearby factories enables a close observation of the interaction between the two types of migrants. Migrant wives tend to draw a clear boundary between themselves and the migrant workers who temporarily reside in Jiangbin for occupational purposes. The differentiation is reflected in migrant wives' sense of inherent superiority. Their remarks on the migrant workers usually encapsulate criticism about young migrant workers' lifestyle and poverty. As Ms. Duan commented on her tenants:

Those young people spend every penny they earn. They do not even think about a future life. All of my tenants paid thousands to purchase the newly popularised water fans [shuishan] last summer. They always go for trendy stuff without thinking of the value. The situation when I left home and married into Zhejiang was so different from now. If I were them, I would definitely tighten the budget and save some money for the future. (Ms. Duan, 44, from Longli, Guizhou, married into Jiangbin in 1996)

With identity-motivated differentiation in place, migrant wives and migrant workers become 'the most familiar strangers' living under the same roof. Xiao Gao, a young worker from Guizhou, told me he did not know that his landlady is originally from Guizhou and that their hometowns are actually quite close:

The only time I talk to the landlady is at the end of each month when she comes up to my room and col- lects the rent. She speaks Xiaoshan dialect to us like the local people, so I did not even realise that she is a fellow Guizhou woman.

The address of 'fellow countryman' (laoxiang) seldom came from the mouths of migrant wives in their daily interaction with migrant workers, however. The intentional differentiation helps migrant wives reinforce their identity as members of the village. The remarks about migrant workers' spending habits and financial statuses serve as a way to divert poverty-related external shame and to transfer that shame onto even more financially inferior individuals in the locality. This observation exemplifies another practice of identity reconstruction, where 'othering' less privileged groups becomes a strategy of migrant wives which allows them merge into the social mainstream.

To summarise, the observations above demonstrate two typical ways to deflect poverty-related shame. Since external shame is conveyed by attitudes, thoughts, and the actions of others, it signifies one's social relations and position in the community. The way migrant wives perceive, handle, and respond to poverty-related shame from external sources is therefore tightly associated with their social identity in the community. The endeavour of integrating into the mainstream and of othering less advantaged members of the community reconstructs the migrant wives' social identity. These dynamics underpin Walker's argument on the fluidity of stigma: The subject of socially produced shame can become the main body of shaming on another occasion (Walker, 2014, pp. 52-53).

\section{Conclusion}

This research article presents a qualitative account of poverty and poverty-related shame based on the phenomenon of inter-provincial marriage in rural China. It resonates with existing empirical studies of China's internal marriage migration by revealing the prevalence of poverty among migrant wives. It outlines the fact that migrant wives usually experience both absolute and relative poverty in their life course and endure perpetuated poverty after marriage. Poverty-related shame marks a key dimension to understanding how poverty is perceived and deflected in migrant wives' everyday life.

Empirical findings suggest that migrant wives' poverty-related shame can be comprehended through two different channels. Internal shame represents migrant wives' personal reflections on insufficiency, whereas external shame demonstrates the influence of socially imposed degradation and exclusion on the impoverished community members. Both internal and external shame are strategically deflected by migrant wives, who aim at minimising its negative impact on their psychological wellbeing and everyday social life. Through recounting misery, migrant wives normalise their experience of poverty as an inevitable product of structural inequality and frame their ability of living with hard- 
ship as a virtue. Through reconstructing identity, migrant wives practice the locality's mainstream values by integrating themselves into the local community and differentiating themselves from other disadvantaged groups in the village, such as migrant workers. Migrant wives are exposed to a series of gender-specific risks, burdens, and social expectations, which make them particularly vulnerable to the psychological and social negativity of poverty. Correspondingly, the way they handle povertyrelated shame is embedded in their gender identity as well. Observations from Jiangbin illustrate the origins and manifestations of poverty. Meanwhile, they exemplify how the psychological and social impacts of poverty are handled and deflected by ordinary residents in everyday life.

\section{Acknowledgments}

The author wishes to thank the anonymous reviewers for their valuable comments on the manuscript. His sincere gratitude also goes to Prof. Robert Walker, Prof. Jane Millar, Prof. Lichao Yang, Prof. Wei Hong, Prof. Jiani He, Ms. Ya Li, Ms. Xiaoying Chen, and Mr. James P. Dawson for their suggestions on the article and support to the research at various stages.

\section{Conflict of Interests}

The author declares no conflict of interests.

\section{References}

Alkire, S., Roche, J. M., Ballon, P., Foster, J., Santos, M. E., \& Seth, S. (2015). Multidimensional poverty measurement and analysis. Oxford: Oxford University Press.

Bossen, L. (2007). Village to distant village: The opportunities and risks of long-distance marriage migration in rural China. Journal of Contemporary China, 16(50), 97-116.

Chang, S. D. (2001). The political economy of uneven development: The case of China. China Review International, 8(1), 254-257.

Chase, E., \& Bantebya-Kyomuhendo, G. (Eds.). (2014). Poverty and shame: Global experiences. New York, NY: Oxford University Press.

Cook, S., \& Dong, X. Y. (2011). Harsh choices: Chinese women's paid work and unpaid care responsibilities under economic reform. Development and Change, 42(4), 947-965.

Daly, M., \& Kelly, G. (2015). Families and poverty: Everyday life on a low income. Bristol: Policy Press.

Davin, D. (1996). Migration and rural women in China: A look at the gendered impact of large-scale migration. Journal of International Development, 8(5), 655-665.

Davin, D. (2005). Marriage migration in China: The enlargement of marriage markets in the era of market reforms. Indian Journal of Gender Studies, 12(2/3), 173-188.
Davin, D. (2007). Marriage migration in China and East Asia. Journal of Contemporary China, 16(50), 83-95.

Davis, D., \& Wang, F. (2009). Creating wealth and poverty in post-socialist China. Stanford, CA: Stanford University Press.

Dollar, D. (2007). Poverty, inequality, and social disparities during China's economic reform (Policy Research Working Paper No. 4253). Washington, DC: World Bank.

Douglas, A. S. (2019). A focus on time-lapse ethnography: Learning to teach. Ethnography and Education, 14(2), 192-205.

Du, Y., Park, A., \& Wang, S. (2005). Migration and rural poverty in China. Journal of Comparative Economics, 33(4), 688-709.

Elder, G. H., Johnson, M. K., \& Crosnoe, R. (2003). The emergence and development of life course theory. In J. T. Mortimer \& M. J. Shanahan (Eds.), Handbook of the life course (pp. 3-19). Boston, MA: Springer.

Ellemers, N., van Knippenberg, A., de Vries, N., \& Wilke, H. (1988). Social identification and permeability of group boundaries. European Journal of Social Psychology, 18(6), 497-513.

Fan, C. C. (1996). Economic opportunities and internal migration: A case study of Guangdong Province, China. The Professional Geographer, 48(1), 28-45.

Fan, C. C. (1999). Migration in a socialist transitional economy: Heterogeneity, socioeconomic and spatial characteristics of migrants in China and Guangdong Province. International Migration Review, 33(4), 954-987.

Fan, C. C., \& Huang, Y. (1998). Waves of rural brides: Female marriage migration in China. Annals of the Association of American Geographers, 88(2), 227-251.

Fan, C. C., \& Li, L. (2002). Marriage and migration in transitional China: A field study of Gaozhou, Western Guangdong. Environment and Planning A, 34(4), 619-638.

Gao, Q. (2017). Welfare, work, and poverty: Social assistance in China. Oxford: Oxford University Press.

Goffman, E. (2009). Stigma: Notes on the management of spoiled identity. New York, NY: Simon and Schuster.

He, C., \& Gober, P. (2003). Gendering interprovincial migration in China. International Migration Review, 37(4), 1220-1251.

Hogg, M. A., \& Terry, D. I. (2000). Social identity and selfcategorization processes in organizational contexts. Academy of Management Review, 25(1), 121-140.

Jiang, Q., Zhang, Y., \& Sánchez-Barricarte, J. J. (2015). Marriage expenses in rural China. China Review, 15(1), 207-236.

Kakwani, N., \& Silber, J. (Eds.). (2008). Many dimensions of poverty. New York, NY: Springer.

Lang, K. (2011). Poverty and discrimination. Princeton, NJ: Princeton University Press.

Li, B. (2005). Urban social change in transitional China: A perspective of social exclusion and vulnerability. Jour- 
nal of Contingencies and Crisis Management, 13(2), 54-65.

Li, Y., \& Wei, Y. D. (2010). The spatial-temporal hierarchy of regional inequality of China. Applied Geography, 30(3), 303-316.

Liang, Z., \& Chen, Y. P. (2004). Migration and gender in China: An origin-destination linked approach. Economic Development and Cultural Change, 52(2), 423-443.

Lister, R. (2013). Power, not pity: Poverty and human rights. Ethics and Social Welfare, 7(2), 109-123.

Medeiros, M. (2006). The rich and the poor: The construction of an affluence line from the poverty line. Social Indicators Research, 78(1), 1-18.

Ravallion, M. (2001). Growth, inequality and poverty: Looking beyond averages. World Development, 29(11), 1803-1815.

Scheff, T. J. (2003). Shame in self and society. Symbolic Interaction, 26(2), 239-262.

Solinger, D. J. (2006). The creation of a new underclass in China and its implications. Environment and Urbanization, 18(1), 177-193.

Stockard, J. E. (1989). Daughters of the Canton Delta: Marriage patterns and economic strategies in South China, 1860-1930. Stanford, CA: Stanford University Press.
Tan, L., \& Short, S. E. (2004). Living as double outsiders: Experiences of marriage in a county-level city. In A. M. Gaetano \& T. Jacka (Eds.), On the move: Women and rural-to-urban migration in contemporary China (pp. 151-175). New York, NY: Columbia University Press.

Walker, R. (2014). The shame of poverty. New York, NY: Oxford University Press.

Walker, R., Bantebya-Kyomuhendo, G., Chase, E., Choudhry, S., Gubrium, E. K., Nicola, J. Y., . . . Ming, Y. (2013). Poverty in global perspective: Is shame a common denominator? Journal of Social Policy, 42(2), 215-233.

Yang, L., \& Walker, R. (2019). Poverty, shame and ethics in contemporary China. Journal of Social Policy. Advance online publication. https://doi.org/10.1017/ S0047279419000667

Zhang, Q. (2018). Cong 'Wailaimei' Dao 'Wailaixi': Hunyin Yimin De Chengshi Shiying Guocheng Yanjiu [From labouring girl to migrant wives: A research on marriage migrants' adaptation to urban life]. Shanghai: Fudan University Press.

Zhang, W. (2009). "A married-out daughter is like spilt water"? Women's increasing contacts and enhanced ties with their natal families in post-reform rural North China. Modern China, 35(3), 256-283.

\section{About the Author}

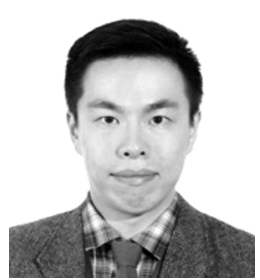

Guanli Zhang joined the Department of Sociology, Tsinghua University, P. R. China, as the Shuimu Tsinghua Post-Doctoral Fellow in 2019, after receiving his PhD from the University of Oxford. He is trained as a social anthropologist specialising in the studies of females, migrants, and other lessprivileged groups in contemporary rural China. He also writes and publishes extensively on environmental knowledge and mobilisation in industrialised and contaminated villages in China. 